\title{
COVID-19: The Awareness of Health-Related Complications of COVID-19 among College Students
}

Martín G. Rosario*, PT, Ph.D., CSFI, ATRIC, Andrea Mathis, SPT, Emily Roberts, SPT

School of Physical Therapy, Texas Woman's University, 5500 Southwestern Medical Ave, Dallas, TX 75235-7299, United States.

\author{
Article Details \\ Article Type: Research Article \\ Received date: $20^{\text {th }}$ April, 2021 \\ Accepted date: $19^{\text {th }}$ June, 2021 \\ Published date: $21^{\text {st } J u n e, ~} 2021$
}

"Corresponding Author: Martin G. Rosario, PT, Ph.D., CSFI, ATRIC, Assistant Professor, School of Physical Therapy, Texas Woman's University, 5500 Southwestern Medical Ave, Dallas, TX 75235-7299, United States. E-mail: mrosario1@twu. edu

Citation: Rosario, M.G., Mathis, A., \& Roberts, E. (2021). COVID-19: The awareness of health-related complications of COVID-19 among college students. J Rehab Pract Res, 2(1):119. https://doi.org/10.33790/jrpr1100119

Copyright: $(2021$, This is an open-access article distributed under the terms of the Creative Commons Attribution License 4.0, which permits unrestricted use, distribution, and reproduction in any medium, provided the original author and source are credited.

\begin{abstract}
s
Background: COVID-19 affects the health and quality of life of the entire world. Despite the toll COVID-19 places on the diverse body systems involving the health of those who suffer from this illness and the communication capabilities of the current era, there are still gaps in information related to the repercussions of this virus.
\end{abstract}

Purpose: To identify the common proficiency of the complications of COVID-19 in a diverse population of college students.

Methods: The present study employed a survey created in Google forms and shared online with students from Texas Woman's University Dallas and Denton Campus.

Results: The complications of COVID-19, which are thoroughly recognized and repeatedly selected, were a sense of smell, changes in taste, loss of appetite, and muscle pain. However, we identified a shortage of awareness regarding the more severe problems of the virus, such as heart failure, heart arrhythmias, liver damage, longterm musculoskeletal issues, and kidney failure.

Conclusion: Despite the health-related complications of COVID-19, the current study determined a disquieting disparity in education attributed to the long-and short-term impairments of this virus. We encourage anyone exposed to COVID-19 or with the possibility of being exposed to delve into all the various health issues created by this virus, such as those alluded to in this report. Future research should focus on strategies to assemble and disseminate the complications associated with COVID-19 more effectively.

\section{Introduction}

In December 2019, a novel coronavirus was discovered in Wuhan, China. Other coronaviruses such as severe acute respiratory syndrome (SARS-CoV) and Middle East respiratory syndrome (MERS-CoV) have been identified previously. Nevertheless, the most recent coronavirus was determined to be an entirely new disease and was named COVID-19 [Sz1] or SARS-CoV-2, according to a report by Amin et al. [1]. The virus spread worldwide from its source and was acknowledged as a pandemic in March 2020 by the World Health Organization (WHO). As of October 2020, over 35 million cases have been documented worldwide, as well as over 1 million deaths from COVID-19, according to the WHO. According to the Centers for
Disease Control and Prevention [SZ2] (2020), people with certain underlying medical conditions such as cancer, chronic obstructive pulmonary disease, heart conditions, obesity, diabetes, and those in an immunocompromised state, are at an increased risk of severe illness from COVID-19 (www.cdc.org). A myriad of COVID-19 research has emerged since the disease surfaced in December 2019 [1]. The condition is well known to disrupt the respiratory system, comparable to its predecessors, but research also indicates that the infection significantly involves many other systems in the human body. The full impact of COVID-19 on a patient's health is not well known [2].

Neurological complications of COVID-19 are theorized to arise when the infection travels through the cribriform plate and olfactory bulb, where it can spread between synapses [3]. According to Montalvan et al. [3] and Nepal et al. [4], the most common neurological manifestations include myalgia, headache, affected sensation, hyposmia, hypogeusia, and altered consciousness. A study by Tong et al. [5] found that the sense of smell is compromised in $52.73 \%$ of cases, and the sense of taste is endangered in $43.93 \%$ of patients, with a strong likelihood that the prevalence of these symptoms is much higher than reported due to invalidated instruments. Furthermore, Montalvan et al. [3] noted that severe neurological conditions such as encephalitis, demyelination, neuropathy, and stroke have also been associated with COVID-19.

The effects of COVID-19 on the cardiovascular system have some of the most severe consequences. Kunutsor et al. [6] found that heart failure, myocardial injury, and arrhythmia were the most common complications of COVID-19 in the heart. Arrhythmia occurs in $19 \%$ of COVID-19 patients, but it has also been identified as a poor prognostic indicator. When identifying difficulties in subjects with poor outcomes, $48 \%$ have experienced arrhythmia [7]. Individuals with pre-existing cardiovascular comorbidities such as hypertension are at a higher risk of developing cardiovascular complications because of SARS-CoV-2, according to research by Shafi et al. [8]. In a study by Lang et al. [9], pericarditis, myocarditis, thrombosis, and arrhythmias were identified concerning COVID-19. Those with significantly elevated cardiac biomarkers have worse outcomes [9].

COVID-19 can also affect the hepatic system. In a study by 
Mao et al. [10], 19\% of cases had an identified liver abnormality in response to COVID-19. These abnormalities include acute hepatic trauma, hypoproteinemia, elevated levels of ALT, AST, and bilirubin, and low levels of albumin, according to Kunutsor et al. [6]. Altered levels of liver enzymes have been associated with a more severe clinical course of COVID-19. Injury to the liver may be due to the infection itself, but could also be induced by the medications used for treatment, conforming to Youssef et al. [11]. Fifteen percent of subjects also experienced manifestations related to gastrointestinal symptoms, including nausea and vomiting, loss of appetite, and diarrhea. Papathanassoglou et al. [12] found acute kidney failure, cell degeneration, and lymphocytic infiltration within the renal system.

COVID-19 also causes problems within the musculoskeletal structure via angiotensin-converting enzyme 2 (ACE2) and a serine protease used by many of the structures within the system, as reported by Disser et al. [13]. Myalgia and generalized weakness have been reported in nearly half of COVID-19 cases. According to their research, it is appropriate to anticipate musculoskeletal problems both in the short and long term. Neurological symptoms may also affect motor control and muscle function in these subjects.

Although research has identified many potential complications of COVID-19, the extent to which the general population knows of its effects is unknown. This research project aims to identify gaps in knowledge of COVID-19 among college students, promote awareness, and educate on the global impact this virus has on the human body.

\section{Methods}

An online survey was dispersed via email and completed by 99 individuals to learn what the public knew about the COVID-19 virus. Ninety-nine participants participated in the COVID-19 survey between October and November 2020. The participants' ages ranged from 18 to 66 years, with the average age of 24.36 years. In addition to age distribution, the participants were from a variety of academic backgrounds, including biology (12.1\%), kinesiology (38.4\%), physical therapy (33.3\%), and others ( $1 \%$ each).

\section{Survey}

The investigators created a survey employing Google Forms based on a literature review. The survey was designed to measure participants' awareness of the effects of COVID-19 on the human body. The study detailed 14 complications of COVID-19, and participants were requested to select those they asserted were correct and assess their confidence in their answers on a scale of 1-10, with 1 being not at all confident and 10 being completely confident.

\section{Procedures}

Participants were apprised that the survey was devised to assess the public's recognition of COVID-19 complications. The participants provided consent to participate in the investigation by willingly contributing to the inquiry. Participants typically completed the questionnaire in less than 10 minutes. At the end of the survey, participants were notified that all the complications listed were accurate.

\section{Data Analysis}

Data was assembled in a spreadsheet for averages and percentages.

\section{Results}

Participant characteristics are summarized in Table-1. Table 1 shows the age and academic backgrounds of the participants. Most of the study participants had an average age of 24 years and were enrolled in Texas Woman's University.

\begin{tabular}{|l|l|}
\hline Characteristics & $\mathbf{N}(\mathbf{\%})$ \\
\hline Age group (mean=24.36 years) & \\
\hline $18-24$ years & $76 \%$ \\
\hline $25-34$ years & $18 \%$ \\
\hline $35-44$ years & $4 \%$ \\
\hline $45-54$ years & $1 \%$ \\
\hline $55-64$ years & $0 \%$ \\
\hline$>65$ years & $1 \%$ \\
\hline Academic Background & \\
\hline Biology & $12 \%$ \\
\hline Kinesiology & $38 \%$ \\
\hline Physical Therapy & $33 \%$ \\
\hline Others & $17 \%$ \\
\hline
\end{tabular}

Table 1: Sample Characteristics (Total Participants $\mathrm{N}=99$ )

Table-2 demonstrates participants' responses to different survey questions. Table 2 features the participants' replies to the survey.

\begin{tabular}{|l|l|l|l|}
\hline Question: & Options & Responses & Percentage \% \\
\hline $\begin{array}{l}\text { 1. According to what } \\
\text { you know, select all } \\
\text { that apply, COVID-19 } \\
\text { can }\end{array}$ & $\begin{array}{l}\text { 1. Have easy direct } \\
\text { access to the brain }\end{array}$ & $18 / 99$ & $18.2 \%$ \\
\cline { 2 - 4 } & $\begin{array}{l}\text { 2. Alter your sense of } \\
\text { smell }\end{array}$ & $97 / 99$ & $98 \%$ \\
\cline { 2 - 4 } & $\begin{array}{l}\text { 3. Change your sense } \\
\text { of taste }\end{array}$ & $98 / 99$ & $99 \%$ \\
\cline { 2 - 4 } & 4. Cause muscle pain & $73 / 99$ & $73.7 \%$ \\
\cline { 2 - 4 } & 5. Cause heart failure & $44 / 99$ & $31.3 \%$ \\
\cline { 2 - 4 } & 6. Cause arrhythmia & $31 / 99$ & \multicolumn{2}{c|}{ Table 2. To be cont... } \\
\hline
\end{tabular}




\begin{tabular}{|c|c|c|c|}
\hline & 7. Cause liver damage & $24 / 99$ & $24.2 \%$ \\
\hline & $\begin{array}{l}\text { 8. Cause nausea and } \\
\text { vomiting }\end{array}$ & $73 / 99$ & $73.7 \%$ \\
\hline & $\begin{array}{l}\text { 9. Cause loss of } \\
\text { appetite }\end{array}$ & $82 / 99$ & $82.8 \%$ \\
\hline & $\begin{array}{l}\text { 10. Cause short term } \\
\text { musculoskeletal issues } \\
\text { such as joint pain }\end{array}$ & $63 / 99$ & $63.6 \%$ \\
\hline & $\begin{array}{l}\text { 11. Cause long term } \\
\text { musculoskeletal issues } \\
\text { such as osteoporosis }\end{array}$ & $20 / 99$ & $20.2 \%$ \\
\hline & $\begin{array}{l}\text { 12. Only preys on the } \\
\text { weak and the old }\end{array}$ & $13 / 99$ & $13.1 \%$ \\
\hline & $\begin{array}{l}\text { 13. Cause kidney } \\
\text { failure }\end{array}$ & $32 / 99$ & $32.3 \%$ \\
\hline & $\begin{array}{l}\text { 14. Be more likely to } \\
\text { cause complications in } \\
\text { individuals with a pre- } \\
\text { existing cardiovascular } \\
\text { disease }\end{array}$ & $83 / 99$ & $83.8 \%$ \\
\hline 2. How confident & A. 0 & $0 / 99$ & $0 \%$ \\
\hline are you about your & B. 1 & $0 / 99$ & $0 \%$ \\
\hline & C. 2 & $2 / 99$ & $2 \%$ \\
\hline & D. 3 & $8 / 99$ & $8.1 \%$ \\
\hline & E. 4 & $8 / 99$ & $8.1 \%$ \\
\hline & F. 5 & $25 / 99$ & $25.3 \%$ \\
\hline & G. 6 & $12 / 99$ & $12.1 \%$ \\
\hline & H. 7 & $27 / 99$ & $27.3 \%$ \\
\hline & I. 8 & $11 / 99$ & $11.1 \%$ \\
\hline & J. 9 & $2 / 99$ & $2 \%$ \\
\hline & K.10 & $4 / 99$ & $4 \%$ \\
\hline 3. Do you know that & A. No & $89 / 99$ & $89.9 \%$ \\
\hline all the complications & B. Yes & 9/99 & $9.1 \%$ \\
\hline $\begin{array}{l}\text { you read above are } \\
\text { true? }\end{array}$ & C. I did not know & $1 / 99$ & $1 \%$ \\
\hline 4. How surprised & A. 0 & $7 / 99$ & $7.1 \%$ \\
\hline were you knowing & B. 1 & $3 / 99$ & $3 \%$ \\
\hline $\begin{array}{l}\text { CUVID-19 can } \\
\text { have all those }\end{array}$ & C. 2 & $6 / 99$ & $6.1 \%$ \\
\hline complications? & D. 3 & $11 / 99$ & $11.1 \%$ \\
\hline & E. 4 & $5 / 99$ & $5.1 \%$ \\
\hline & F. 5 & $3 / 99$ & $3 \%$ \\
\hline & G. 6 & $10 / 99$ & $10.1 \%$ \\
\hline & H. 7 & $7 / 99$ & $7.1 \%$ \\
\hline & I. 8 & \begin{tabular}{|l|}
$18 / 99$ \\
\end{tabular} & $18.2 \%$ \\
\hline & J. 9 & \begin{tabular}{|l|}
$13 / 99$ \\
\end{tabular} & $13.1 \%$ \\
\hline & K. 10 & \begin{tabular}{|l|}
$16 / 99$ \\
\end{tabular} & $16.2 \%$ \\
\hline
\end{tabular}

Table 2: Participant's response to survey and percentage

The results revealed four main discoveries from the survey replies. First, some symptoms of COVID-19 are well recognized, such as an altered sense of smell (99\%), changes in taste (98\%), loss of appetite (82.8\%), and muscle pain (74\%). However, the second main finding showed that complications such as heart failure (44\%), heart arrhythmias (31\%), liver damage (24\%), long-term musculoskeletal issues (20\%), and kidney failure (32\%) were established by fewer than half of the participants. Third, most participants were considerably confident in their responses, with $64.7 \%$ ranking their confidence between $5-7 / 10$. Finally, $89.9 \%$ of the participants were unaware that all the problems listed were possible after the COVID-19 infection. 


\section{Discussion}

This study aimed to determine the perceptions of undergraduate and graduate students regarding the implications of COVID-19. This study demonstrates a lack of awareness of the effects of COVID-19 on the human body despite the vast spread of the virus. This scarcity of understanding demonstrates the necessity for increased public education regarding the long-term consequences of the virus. While research compiled by the CDC shows that COVID-19 can implicate nearly all body systems, the majority of participants in this study were primarily aware of short-term consequences rather than longterm effects such as changes to the heart, liver, and kidney.

Despite extensive research on the consequences of COVID-19, there is inadequate knowledge shown by the current study results. The first main finding from this study was that participants identified altered smell (98\%), changes in taste $(99 \%)$, loss of appetite $(82.8 \%)$, and muscle pain $(74 \%)$ as the four most common signs and symptoms of COVID-19 (Table 2). As previously mentioned, more than half of the people infected with COVID-19 reported a compromised sense of smell, taste [5], and muscle pain [13], and as these complications are most common, they are also typically associated with this virus. Although the mechanism by which COVID-19 attacks the olfactory nerves and the musculoskeletal system is complex [5, 13], the shortand long-term complications of both of these areas are anticipated.

The second primary outcome from this study was that participants were less likely to choose heart failure (44\%), arrhythmias $(31 \%)$, liver complications (24\%), long-term musculoskeletal issues $(20 \%)$, and kidney failure (32\%) as additional complications of COVID-19. Although Mao et al. [10] and Kunutsor et al. [14] found that COVID-19 can cause acute injury to the liver and altered enzyme levels, liver damage is one of the least known effects of the disease. A few participants also selected kidney failure, although studies including Shafi et al. [8] have previously identified it as a possible development of COVID-19. Furthermore, fewer than 50\% of participants identified heart arrhythmias and heart failure as potential effects of the virus, despite the common arrhythmias in COVID patients and how these symptoms are often used to indicate a poor prognosis, as described by Pranata et al. [7]. Although $84 \%$ correctly believed that COVID-19 could be more complicated in those with pre-existing heart conditions, issues such as pericarditis, myocarditis, and thrombosis are severe conditions that Lang et al. [9] identified as being related to infection by COVID-19. The least known consequence of COVID-19 is long-term musculoskeletal issues, despite the widespread recognition of short-term musculoskeletal conditions, such as muscle pain. Disser et al. [13] studied the effects of COVID-19 on the musculoskeletal system, and coronaviruses patients were identified to be at risk of long-term issues such as sarcopenia and osteoporosis. However, only $20 \%$ of the participants were aware of these potential issues.

The third main finding of this study was that most participants were unable to identify all the complications of COVID-19. This survey was conducted to explore what the participants knew about the effects of COVID-19. The participants were then asked to respond to how confident they were in their knowledge. Most participants were partly confident in their responses. Towards the end of the survey, the last questions were set up to educate the participants on the fact that all of the signs and symptoms listed were effects of COVID-19 and poll the reaction after being given that information. These results indicate a need for greater education of the public on the more serious, long-term effects of COVID-19, which range much further than loss of taste and smell.

\section{Conclusion}

This study demonstrates the necessity for adequate education of the public regarding COVID-19. Limited research is available on the public's awareness of the symptoms and long-term effects of the disease prior to this study. Liu et al. [2] assessed the recognition of symptoms in their research. The discoveries were similar to the results of this survey, with fever, cough, and debilitation being recognized by at least $90 \%$ of the participants. However, nasal congestion and rhinorrhea were observed in less than $50 \%$ of cases. Other previous research by Liu et al. [2], Lee et al. [15], and Hussain et al. [16] have focused on awareness of routes of transmission, effective methods to prevent the spread of the disease, and psychological effects of living during a pandemic. Further research and dissemination of research are needed for the general public to become knowledgeable about symptoms that indicate COVID-19 infection and how that can affect the body in the long term.

This study was conducted mainly on undergraduate and graduate students at Texas Woman's University. It would be pertinent for future studies to assess the awareness of other populations, such as those without any college education or older adults who are more affected by the virus, to obtain an accurate measure of the public's knowledge. A look at the understanding of COVID-19 on a global scale would also be pertinent as the disease is considered a global pandemic. Studies analyzing people's perceptions of the consequences of COVID may also help to learn more about the effects of the virus. In the future, research concerning the sources people use for information about the virus and their preferred learning method may be necessary to determine how to educate the public about COVID-19 effectively.

\section{Funding Statement: N/A}

Ethics and Consent: The author utilized the ARECCI tool to stipulate and justify that this examination is classified under the Program Quality Improvement, for which the ARECCI tool is advised instead of an institutional review board. This report can be accessed at this URL.

http://www.aihealthsolutions.ca/arecci/screening/456003/ebcb1e50a a3482d306acc0efcb99b51b

Conflict of Interest Statement: The authors declare no conflict of interest.

Authors' contributions: All authors contributed to the study conception and design.

\section{References}

1. Amin, S. D., Moghadam, M. T., \& Satarzadeh, N. (2020). COVID-19 (coronavirus disease 2019): A new coronavirus disease. Infection and Drug Resistance, 13, 2819-2828. doi:http://dx.doi.org.ezp.twu.edu/10.2147/IDR.S259279

2. Liu, Y., Wang, D., Xu, H., Xiao, Y., Chen, C., Chen, R.-N., Hu, L.-H., \& Li, Z.-S. (2021). A snapshot of public knowledge of novel coronavirus disease 2019: a web-based national survey. BMC Public Health, 21(1), 1-10. https://doi-org.ezp.twu. edu/10.1186/s12889-021-10495-4

3. Montalvan, V., Lee, J., Bueso, T., De Toledo, J., \& Rivas, K. (2020). Neurological manifestations of COVID-19 and other coronavirus infections: A systematic review. Clinical neurology and neurosurgery, 194, 105921. https://doi.org/10.1016/j. clineuro.2020.105921

4. Nepal, G., Rehrig, J. H., Shrestha, G. S., Shing, Y. K., Yadav, J. K., Ojha, R., Pokhrel, G., Tu, Z. L., \& Huang, D. Y. (2020). Neurological manifestations of COVID-19: a systematic review. Critical care (London, England), 24(1), 421. https://doi. org/10.1186/s13054-020-03121-z

5. Tong, J. Y., Wong, A., Zhu, D., Fastenberg, J. H., \& Tham, T. (2020). The Prevalence of Olfactory and Gustatory Dysfunction in COVID-19 Patients: A Systematic Review and Meta-analysis. Otolaryngology--head and neck surgery: official journal of American 
6. Kunutsor, S. K., \& Laukkanen, J. A. (2020). Cardiovascular complications in COVID-19: A systematic review and metaanalysis. Journal of Infection, 81(2), e139-e141. https://doi-org. ezp.twu.edu/10.1016/j.jinf.2020.05.068

7. Pranata, R., Huang, I., \& Raharjo, S. B. (2020). Incidence and impact of cardiac arrhythmias in coronavirus disease 2019 (COVID-19): A systematic review and meta-analysis. Indian pacing and electrophysiology journal, S09726292(20)30087-5. Advance online publication. https://doi. org/10.1016/j.ipej.2020.08.001 Academy of OtolaryngologyHead and Neck Surgery, 163(1), 3-11. https://doi. org $/ 10.1177 / 0194599820926473$

8. Shafi, A. M., Shaikh, S. A., Shirke, M. M., Iddawela, S., \& Harky, A. (2020). Cardiac manifestations in COVID-19 patients-A systematic review. Journal of Cardiac Surgery,35(8), 19882008. doi:10.1111/jocs. 14808

9. Lang, J. P., Wang, X., Moura, F. A., Siddiqi, H. K., Morrow, D. A., \& Bohula, E. A. (2020). A current review of COVID-19 for the cardiovascular specialist. American Heart Journal, 226, 29-44. https://doi-org.ezp.twu.edu/10.1016/j.ahj.2020.04.025

10. Mao, R., Qiu, Y., He, J. S., Tan, J. Y., Li, X. H., Liang, J., Shen, J., Zhu, L. R., Chen, Y., Iacucci, M., Ng, S. C., Ghosh, S., \& Chen, M. H. (2020). Manifestations and prognosis of gastrointestinal and liver involvement in patients with COVID-19: a systematic review and meta-analysis. The lancet. Gastroenterology \& hepatology, 5(7), 667-678. https://doi.org/10.1016/S24681253(20)30126-6

11. Youssef, M., Hussein, M., Attia, A. S., Elshazli, R., Omar, M., Zora, G., ... Kandil, E. (2020). COVID-19 and liver dysfunction: A systematic review and meta-analysis of retrospective studies. Journal of Medical Virology, 92(10), 1825-1833. https://doi. org/10.1002/jmv.26055
12. Papathanassoglou, E., Pohar Manhas, K., \& Kusi-Appiah, E. (2020). Beyond Acute Respiratory Distress: Multiple Organ Effects and Early Rehabilitation in COVID-19. CONNECT: The World of Critical Care Nursing, 13(4), 155-161. https:// doi-org.ezp.twu.edu/10.1891/WFCCN-D-20-00008

13. Disser, Nathaniel, De Micheli, Andrea, Schonk, Martin, Konnaris, Maxwell, Piacentini, Alexander, Edon, Daniel, et al. (2020). Musculoskeletal consequences of COVID-19. Journal of Bone \& Joint Surgery - American Volume, 102, 1197-1204. https://doi.org/10.2106/JBJS.20.00847

14. Kunutsor, S. K., \& Laukkanen, J. A. (2020). Hepatic manifestations and complications of COVID-19: A systematic review and meta-analysis. Journal of Infection,81(3). doi:10.1016/j.jinf.2020.06.043

15. Lee, M., Kang, B.-A., \& You, M. (2021). Knowledge, attitudes, and practices (KAP) toward COVID-19: a cross-sectional study in South Korea. BMC Public Health, 21(1), 1-10. https://doiorg.ezp.twu.edu/10.1186/s12889-021-10285-y

16. Hussain, T., Gilani, U. S., Khan, S., \& Raza, S. M. (2021). Assessment of general awareness among Pakistani students regarding COVID-19 outbreak. Children and Youth Services Review, 121, 105830. https://doi.org/10.1016/j. childyouth.2020.105830 